\title{
Fatores que influenciam a concentração de íons cloreto na atmosfera urbana de Aracaju/SE
}

Factores influencing the concentration of chloride ions in the urban atmosphere of Aracaju/SE.

\author{
Ana Larissa Cruz Prata ${ }^{1}$ (D) orcid.org/ 0000-0003-1324-8171 \\ Carlos Henrique de Carvalho ${ }^{1}$ (D) orcid.org/0000-0002-9839-7813 \\ Francisco Luiz Gumes Lopes ${ }^{2}$ (i) orcid.org/0000-0001-5054-9331 \\ ${ }^{1}$ Departamento de Engenharia Civil, Instituto Federal de Ciência, Educação e Tecnologia de Sergipe, Aracaju, Brasil. \\ 2 Departamento de Química, Instituto Federal de Ciência, Educação e Tecnologia de Sergipe, Aracaju, Brasil. \\ E-mail do autor principal: Ana Larissa Cruz Prata analarissacprata@gmail.com
}

\section{Resumo}

$\mathrm{O}$ ataque de cloretos às estruturas de concreto armado tem sido objeto de muitas pesquisas, pois diante das diretrizes normativas de desempenho, garantir a durabilidade de uma edificação é requisito imperioso diante da vida útil mínima exigida de 50 anos. Com o intuito de subsidiar os projetistas, este estudo teve como objetivo a determinação e avaliação das concentrações de cloreto, em alguns pontos da atmosfera urbana de Aracaju/SE. Para quantificar o teor de cloretos utilizou-se a cromatografia iônica e o método de Mohr. A partir dos resultados, observou-se a influência da concentração de cloreto na distância em relação ao mar, altitude, parâmetros climáticos e presença de obstáculos verticais.

Palavras-Chave: Durabilidade; Concreto armado; Cloreto;

\begin{abstract}
The attack of chlorides on reinforced concrete structures has been the subject of much research, since in view of normative performance guidelines, guaranteeing the durability of a building is an imperative requirement given the minimum required life of 50 years. In order to subsidize the designers, this study had as objective the determination and evaluation of the concentrations of chloride, in some points of the urban atmosphere of Aracaju / SE. To quantify the chloride content, the ion chromatography and the Mohr method were used. From the results, the influence of the chloride concentration in the distance in relation to the sea, altitude, climatic parameters and presence of vertical obstacles was observed.
\end{abstract}

Key-words: Durability; Reinforced Concrete; Chlorides; 


\section{Introdução}

Culturalmente, o único parâmetro que os projetistas se preocupavam para atingir a durabilidade das estruturas de concreto, era a capacidade resistente, isto é, apenas propriedades mecânicas. Porém, na virada da década de 1960 para 1970, os projetistas sentiram a necessidade de pesquisar novos critérios para garantir o total sucesso das construções [1], visto que estruturas com 20 a 30 anos de idade, já apresentavam problemas significativos de deterioração. [2]

Um exemplo de manifestação patológica recorrente em estruturas de concreto armado no Brasil é a corrosão de armaduras. Essa manifestação está diretamente associada à durabilidade de estruturas de concreto, e a difusão de cloretos é reconhecida como um dos fatores de maior importância no desencadeamento do processo corrosivo. [3]

Os cloretos em sua maioria, são provenientes de águas marinhas e constituem cerca de $55 \%$ da composição da água do mar, conforme a Figura 1. Como o Brasil possui uma extensa faixa litorânea e $26,58 \%$ da população brasileira reside em zonas costeiras [4], as estruturas localizadas próximas a região de mar são fortemente atacadas pelo íon cloreto.

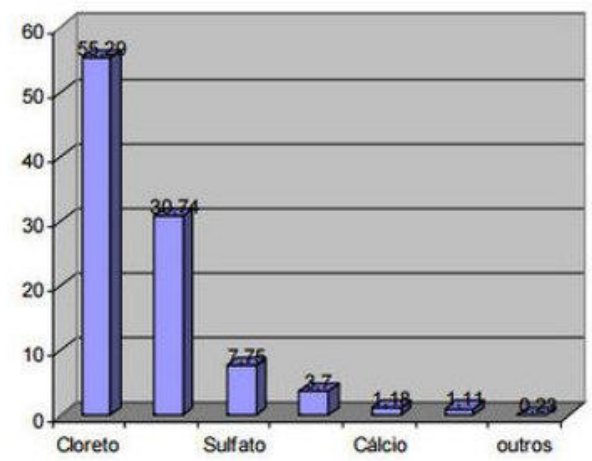

Figura 1: Composição dos íons da água do mar. Fonte: Lima et al. (2005) [5]

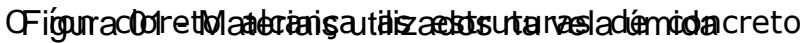
através do aerossol marinho transportado pelo vento, ocasionam corrosões localizadas agressivas que levam às desagregações dos cobrimentos protetores das armaduras embutidas, comprometendo o desempenho e a durabilidade do componente estrutural.

Diante de estudos realizados no Brasil sobre concentrações de cloretos, mais especificamente nas 93 capitais do Nordeste, de cidades como Fortaleza/CE, São Luís/MA, Recife/PE, Maceió/AL e Salvador/BA, houve a necessidade de realizar o estudo pioneiro em Aracaju/SE para obter o conhecimento das concentrações e os fatores que influenciam esses íons agressivos em regiões urbanas imobiliárias, propiciando aos projetistas estruturais, construtores e proprietários, um mapeamento com informações técnicas fundamentais à garantia da segurança e durabilidade no uso da edificação através desse mapeamento.

\section{Metodologia}

\subsection{Método de coleta}

A determinação do teor de cloreto é fundamentada pela ABNT NBR 6211:2001 [6] que se baseia na norma americana ASTM D 512-89:1999 [7]. A medição é realizada através de um equipamento chamado "vela úmida". Esse equipamento consiste em um Erlenmeyer (frasco coletor) com água glicerinada, ao qual é introduzido um tubo de ensaio enrolado com uma gaze. Por ascensão capilar, a gaze fica úmida e consegue capturar os íons presentes no ar que entram em contato com ela, e pelo mecanismo de difusão estes íons se movem para o interior da solução presente no frasco coletor. [8]

A vela úmida deste trabalho (Figuras 2 e 3 ) teve seu material de suporte em madeira, a cobertura em alumínio, o frasco coletor de vidro do tipo Erlenmeyer de boca larga com capacidade de $1.000 \mathrm{~mL}$, a vela coletora constituída de um tubo de ensaio de vidro com diâmetro de $2,5 \mathrm{~cm}$ e os tubos que drenam as gazes para o interior do frasco coletor são tubos de ensaio em vidro de diâmetro $1,5 \mathrm{~cm}$. A vedação do frasco de Erlenmeyer foi realizada com tampão de PVC. Todos os tubos de ensaio foram fixados no tampão com massa epóxi resistente, já que o equipamento estaria exposto as condições climáticas do ambiente. Ressalta-se que o equipamento foi confeccionado conforme a ABNT NBR 6211:2001. 


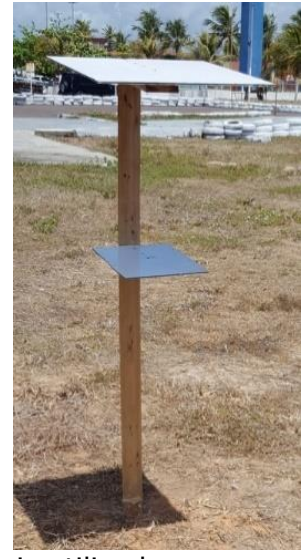

Figura 2: Materiais utilizados no suporte da vela úmida. Fonte: Autores (2017)

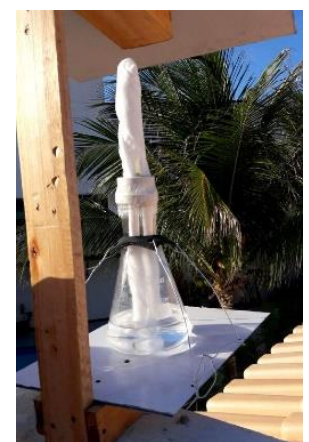

Figura 3: Materiais utilizados na vela úmida. Fonte: Autores (2017).

\subsection{Localização das velas úmidas}

A pesquisa foi desenvolvida na região de Aracaju/SE, no período de abril/2017 a agosto/2017, em bairros ocupados e de futura expansão urbana. Os critérios para instalação dos pontos foram de acordo com pesquisas realizadas em outros estados, pois não haviam registros desse tipo de pesquisa na região de Aracaju/SE. Os critérios foram: instalação próxima a faixa litorânea, localização mais adentro do município para analisar a deposição de cloretos em relação a distância ao mar, próxima a locais que possuem concentração de obstáculos verticais (prédios) e instalações em alturas variadas para verificar a influência do parâmetro altitude. A Figura 4 apresenta a localização das dez estações que foram dispostas as velas úmidas. $\mathrm{Na}$ Tabela 1 , são apresentadas informações quanto as estações, tais como as distâncias ao mar e as altitudes. Ressalta-se que as estações instaladas em coberturas de edificações tiveram como cota resultante o somatório do nível do terreno mais a altura da edificação.

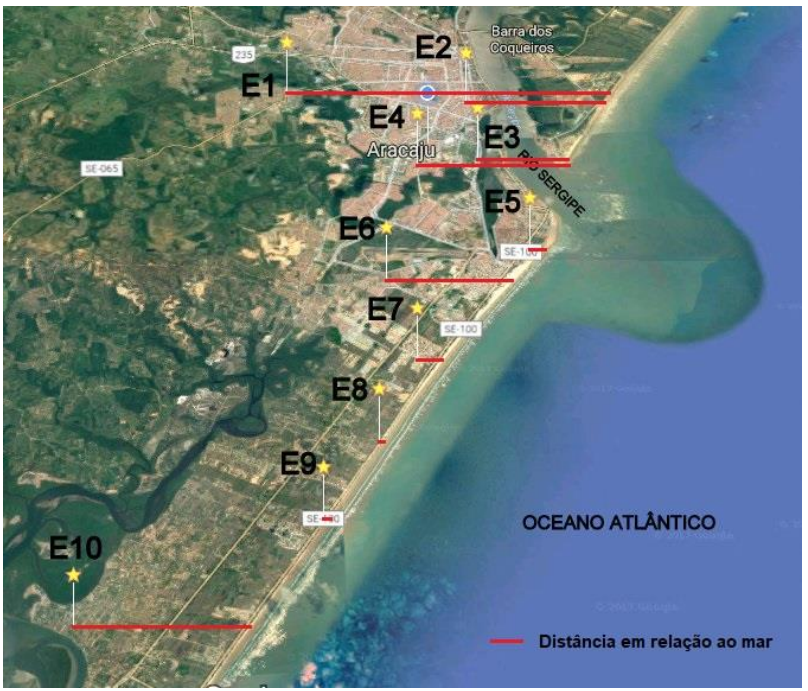

Figura 4: Localização dos equipamentos da vela úmida. Fonte: Autores (2017)

Tabela 1: Informações dos locais de exposição da vela úmida.

\begin{tabular}{|c|c|c|c|}
\hline Estação & $\begin{array}{l}\text { Bairro/Local } \\
\text { de instalação }\end{array}$ & $\begin{array}{c}\text { Altitude } \\
\text { (m) }\end{array}$ & $\begin{array}{c}\text { Distância em } \\
\text { relação ao } \\
\operatorname{mar}(\mathbf{m})\end{array}$ \\
\hline E1 & Rosa Elze - UFS & 13,40 & $10.434,09$ \\
\hline E2 & $\begin{array}{c}\text { Salgado Filho - } \\
\text { Propriedade } \\
\text { Privada }\end{array}$ & 8,95 & $4.391,00$ \\
\hline E3 & $\begin{array}{l}\text { Jardins - } \\
\text { EMBRAPA }\end{array}$ & 4,00 & $2.659,33$ \\
\hline E4 & $\begin{array}{c}\text { Inácio Barbosa - } \\
\text { Propriedade } \\
\text { Privada } \\
\end{array}$ & 8,75 & $4.317,33$ \\
\hline E5 & $\begin{array}{c}\text { Atalaia - } \\
\text { Kartódromo }\end{array}$ & 5,00 & 448,29 \\
\hline E6 & $\begin{array}{c}\text { Aeroporto - } \\
\text { Propriedade } \\
\text { Privada }\end{array}$ & 11,90 & $3.452,94$ \\
\hline E7 & $\begin{array}{c}\text { Aruanda - } \\
\text { Propriedade } \\
\text { Privada }\end{array}$ & 7,00 & 698,39 \\
\hline E8 & $\begin{array}{c}\text { Mosqueiro - } \\
\text { Propriedade } \\
\text { Privada } \\
\end{array}$ & 6,00 & 111,02 \\
\hline E9 & $\begin{array}{c}\text { Mosqueiro - } \\
\text { Propriedade } \\
\text { Privada }\end{array}$ & 9,40 & 116,19 \\
\hline E10 & $\begin{array}{l}\text { Mosqueiro - } \\
\text { Propriedade } \\
\text { Privada }\end{array}$ & 10,00 & $4.034,64$ \\
\hline
\end{tabular}

Fonte: Autores (2017)

As Figuras 5 e 6 ilustram exemplos de estações instaladas em Aracaju/SE. 


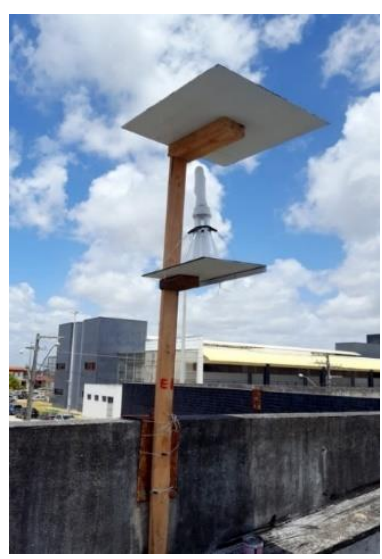

Figura 5: Estação 01 (UFS) instalada na cobertura da edificação.

Fonte: Autores (2017).

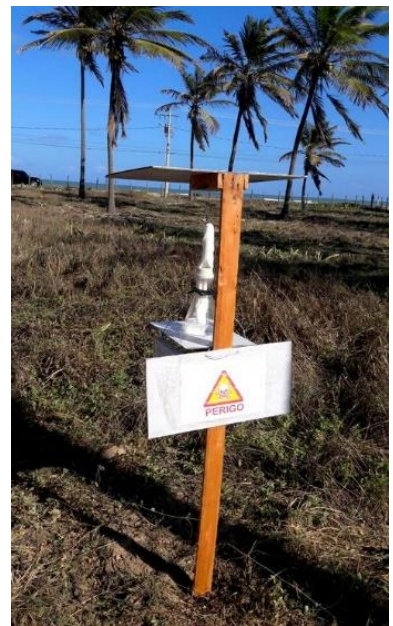

Figura 6: Estação 08 (Mosqueiro) instalada no solo. Fonte: Autores (2017).

\subsection{Procedimento de coleta}

Após os 30 dias de exposição, período de tempo recomendado pela ABNT NBR 6211:2001, iniciou-se o procedimento de coleta. Para obter a concentração de cloreto foi necessário coletar a solução do frasco coletor e as gazes. Essas foram armazenadas em um pote com $200 \mathrm{ml}$ de água destilada, para em seguida, iniciar o processo de lavagem com o objetivo de retirar os íons cloretos ainda retidos nas gazes.

\subsection{Determinação da concentração de cloreto}

Para a determinação dos íons cloretos foi utilizada a cromatografia iônica, que é um método físico-químico eficaz e preciso na determinação da concentração de íons em determinada solução [9]. Pelo fato da cromatografia de íons não efetuar leituras de amostras com condutividades maiores que $1.000 \mathrm{mS}$, essas foram analisadas pelo método volumétrico de Mohr [10] [11].

O teor de cloretos expresso na cromatografia de íons e no método de Mohr obtidos em mg. $\mathrm{L}^{-1}$, foram convertidos em mg.( $\mathrm{m}^{2}$.dia $)^{-1}$ conforme a ABNT NBR 6211:2001 e representada na equação 1 .

$$
\text { Cloreto }\left(\frac{m g}{m^{2}} \cdot \text { dia }\right)=\frac{\text { Cloreto }\left(\frac{m g}{L}\right) x v t}{A x t}
$$

Onde:

$\mathrm{Vt}=$ volume total da amostra, em litros;

$A$ = área de exposição da gaze, em metros quadrados;

$\mathrm{t}=$ tempo de exposição, em dias.

\section{Resultados e Discussões}

\subsection{Análise climatológica}

Durante o período da pesquisa a caracterização climatológica apresentou-se de acordo com as Tabelas 2 e 3.

Tabela 2: Informações climáticas durante a pesquisa.

\begin{tabular}{c|c|c|c}
\hline Período & $\begin{array}{c}\text { Temp. } \\
\left({ }^{\circ} \mathbf{C}\right)\end{array}$ & UR (\%) & $\begin{array}{c}\text { Precipitação } \\
(\mathbf{m m})\end{array}$ \\
\hline $\begin{array}{c}\text { Abril/ } \\
17\end{array}$ & 28,26 & 64,38 & 84,30 \\
\hline $\begin{array}{c}\text { Maio/ } \\
17\end{array}$ & 27,54 & 66,54 & 100,60 \\
\hline $\begin{array}{c}\text { Junho/ } \\
17\end{array}$ & 27,65 & 70,94 & 339,40 \\
\hline $\begin{array}{c}\text { Julho/ } \\
17\end{array}$ & 25,72 & 68,07 & 305,30 \\
\hline $\begin{array}{c}\text { Agosto/ } \\
17\end{array}$ & 24,57 & 68,17 & 116,60 \\
\hline
\end{tabular}

Fonte: Autores (2017)

Tabela 3: Informações climáticas do vento durante a pesquisa.

\begin{tabular}{c|c|c|c}
\hline Período & $\begin{array}{c}\text { Vel. Do } \\
\text { vento } \\
\mathbf{( k m / h )}\end{array}$ & $\begin{array}{c}\text { Rajada do } \\
\text { vento } \\
\mathbf{( k m / h )}\end{array}$ & $\begin{array}{c}\text { Direção do } \\
\text { vento }\left({ }^{\circ}\right)\end{array}$ \\
\hline $\begin{array}{c}\text { Abril/ } \\
17\end{array}$ & 9,25 & 18,23 & 95,37 \\
\hline $\begin{array}{c}\text { Maio/ } \\
17\end{array}$ & 8,86 & 16,32 & 111,59 \\
\hline $\begin{array}{c}\text { Junho/ } \\
17\end{array}$ & 8,50 & 17,26 & 112,51 \\
\hline $\begin{array}{c}\text { Julho/ } \\
17\end{array}$ & 8,89 & 23,40 & 111,24 \\
\hline $\begin{array}{c}\text { Agosto/ } \\
17\end{array}$ & 4,82 & 18,58 & 117,46 \\
\hline
\end{tabular}

Fonte: Autores (2017) 
Evidenciou-se que a temperatura e a umidade apresentaram uma variação pequena e um resultado esperado, pois no período de maior precipitação pluviométrica a umidade relativa também foi maior. Os parâmetros do vento, como velocidade, rajada e direção também apresentaram o mesmo comportamento quanto a variação. Analisando a Tabela 3, o valor da rajada do vento em Julho/2017, alcançou o maior índice e contribuiu para que as partículas salinas, alcançassem maiores distâncias, e consequentemente, adentrassem mais na superfície terrestre.

A precipitação pluviométrica foi o parâmetro climático que mais apresentou variação durante o estudo, o índice de chuvas comparando o primeiro e o terceiro mês de coleta, quadruplicou. Em vista disso, a elevada precipitação promoveu a lavagem das fachadas dos prédios na região de estudo, o que para corrosão de armaduras desencadeadas por cloretos, é uma vantagem, pois elimina os íons cloretos que futuramente poderia desenvolver uma patologia na edificação.

\subsection{Fatores que influenciam concentração de cloreto}

Os resultados do teor de íons cloretos na atmosfera urbana de Aracaju/SE entre os meses de abril/2017 e agosto/2017, são apresentados, na Tabela 4.

Tabela 4: Concentrações de cloreto em mg. $\left(\mathrm{m}^{2} \cdot \mathrm{dia}\right)^{-1}$, durante o período da pesquisa.

\begin{tabular}{c|c|c|c|c|c|c}
\hline Estação & $\begin{array}{c}\text { Abril/ } \\
\mathbf{1 7}\end{array}$ & $\begin{array}{c}\text { Maio/ } \\
\mathbf{1 7}\end{array}$ & $\begin{array}{c}\text { Junho/ } \\
\mathbf{1 7}\end{array}$ & $\begin{array}{c}\text { Julho/ } \\
\mathbf{1 7}\end{array}$ & $\begin{array}{c}\text { Agosto/ } \\
\mathbf{1 7}\end{array}$ & Média \\
\hline E1 & 3,79 & 0,90 & 10,26 & 25,56 & 19,95 & 12,09 \\
\hline E2 & 10,48 & 23,52 & 5,76 & 25,04 & 25,06 & 17,97 \\
\hline E4 & 14,20 & 5,53 & 11,72 & 47,98 & 31,61 & 22,21 \\
\hline E5 & 290,42 & 165,36 & 587,97 & 864,85 & 649,30 & 511,59 \\
\hline$E 6$ & 10,67 & 0,44 & 6,81 & 21,49 & 27,62 & 13,41 \\
\hline E7 & 24,56 & 31,58 & 26,77 & 93,45 & 29,74 & 41,22 \\
\hline$E 8$ & $-*$ & 432,28 & 632,01 & 1621,36 & $-*$ & 895,22 \\
\hline$E 9$ & 179,76 & 361,98 & 422,30 & 1290,77 & 649,70 & 580,90 \\
\hline$E 10$ & 8,27 & 5,32 & 11,79 & 20,11 & 21,22 & 13,34 \\
\hline
\end{tabular}

do Durante a coleta foi constatada que a estação por conta determinação da concentração de cloreto.

Fonte: Autores (2017)

\subsubsection{Altitude}

Em pesquisa realizada para analisar a influência da altitude na concentração de cloreto, em uma edificação localizada na Barra da Tijuca no Rio de Janeiro, a $700 \mathrm{~m}$ do mar, constataram que os pilares de sustentação do térreo, após perícia, foram os que mais apresentaram corrosão de armadura, devido a corrosão atmosférica, em comparação com os pilares dos pavimentos superiores [12].

Esse efeito, se deve à presença de partículas maiores, que são fortemente influenciadas pelo efeito da gravidade, fazendo com que não alcancem níveis muito elevados em atitude e depositem-se mais rápido [13].

Diante disso, observou-se nesta pesquisa uma concentração média de cloretos superior na estação E8, quando comparada com a estação E9, pelo fato da diferença de altitude entre elas. Enquanto a estação E8 foi instalada a uma altitude de $6 \mathrm{~m}$ possuindo uma concentração média de cloreto de 895,22 mg.( $\mathrm{m}^{2}$.dia $)^{-1}$, a estação E9 por estar instalada a $9,40 \mathrm{~m}$ de altitude apresentou uma concentração média de cloretos de 580,90 mg.( $\mathrm{m}^{2}$.dia $)^{-1}$.

\subsubsection{Presença de obstáculos}

A influência da presença de obstáculos verticais, na concentração de cloreto, foi verificada nas estações E2 e E7.

A estação E2 foi instalada no bairro Salgado Filho, sendo esse localizado atrás do Bairro Treze de Julho. Atualmente esse bairro exibe uma grande concentração de prédios, principalmente na avenida Beira Mar (Figuras 7 e 8), o que pode ter influenciado na baixa média da concentração de cloretos, de aproximadamente $17,97 \mathrm{mg} .\left(\mathrm{m}^{2} \text {.dia }\right)^{-1}$, apesar da estação estar situada a $8,95 \mathrm{~m}$, na cobertura da edificação (casa). Isso deve-se ao fato do vento, responsável pelo transporte de partículas salinas, ao adentrar pelo bairro Treze de Julho encontrar barreiras, onde a maioria das partículas se depositam, restando apenas uma pequena parcela do vento contendo sais, que consegue contornar esses obstáculos e adentrar mais a superfície. 


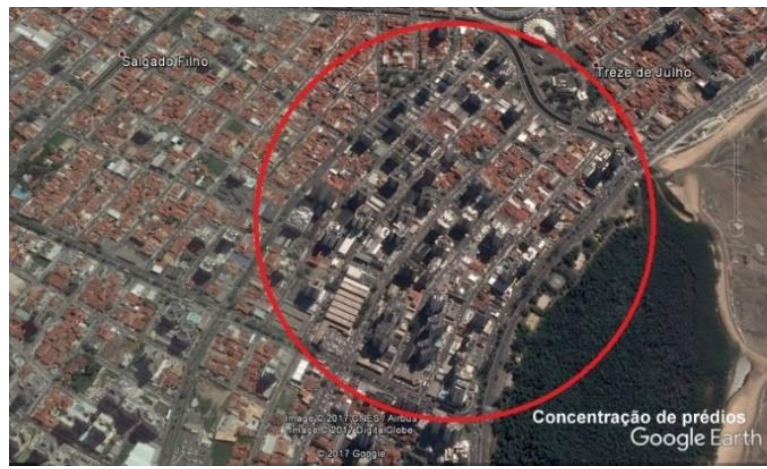

Figura 7: Mapa em 3D da concentração de prédios no Bairro Treze de Julho.

Fonte: Autores (2017).

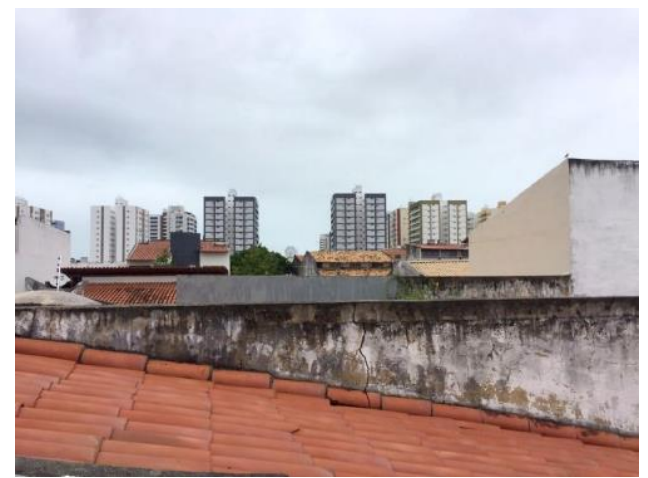

Figura 8: Vista dos prédios da estação E2.

Fonte: Autores (2017).

A estação $\mathrm{E7}$, apesar de estar localizada em região de praia, a menos de $1 \mathrm{~km}$ do mar, sofreu a influência do obstáculo vertical (Figura 9), pois apresentou uma baixa média na concentração de cloreto, de aproximadamente $41,22 \quad \mathrm{mg} \cdot\left(\mathrm{m}^{2} \cdot \mathrm{dia}\right)^{-1}$. Essa influência pode ser confirmada, ao realizar uma comparação com a estação E5 que se localiza a 250m da estação E7. Apesar da proximidade, a estação E5 apresentou uma concentração maior, uma média de $511,59 \mathrm{mg} .\left(\mathrm{m}^{2} \cdot \mathrm{dia}\right)^{-1}$, resultando em uma concentração $91,94 \%$ superior a concentração de cloreto da estação E7.

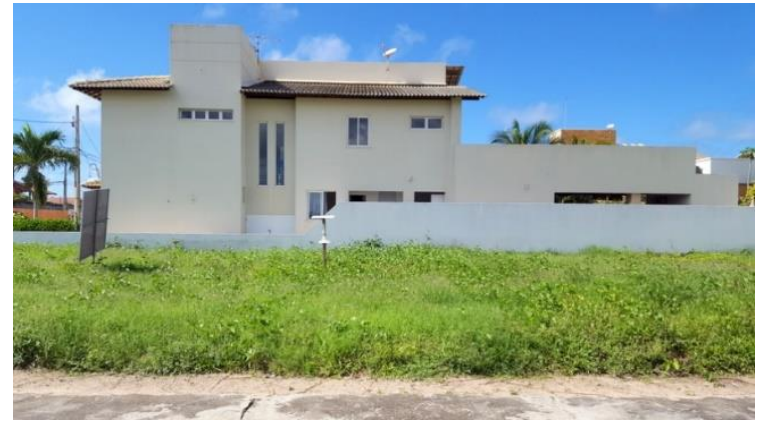

Figura 9: Obstáculo vertical que influenciou a concentração da estação E7. Fonte: Autores (2017).
Um exemplo dessa influência também foi constatado em um estudo realizado em Salvador/BA [14] através da atualização do mapa de agressividade da região. A partir de uma nova variável, caracterizada pela altura das edificações, foram identificados bairros com forte agressividade ambiental até o limite de 360 metros, enquanto que no mapa de Vilasboas (2013) [8] a extensão de forte agressividade ambiental se estendia a uma distância igual ou inferior a 400 metros da orla marítima.

\subsubsection{Distância em relação ao mar}

A distância em relação ao mar é um fator influenciado tanto pelo efeito gravimétrico quanto pelo vento. O efeito gravimétrico faz com que as partículas de sais, de maior diâmetro, por serem mais pesadas, não alcançam grandes distâncias nem alturas, e se depositam próximas ao mar [15], como demonstra as estações E5, E8 e E9 (Figura 10), que por serem as mais próximas ao mar apresentaram as maiores concentrações de cloreto. O fator climático vento influencia no transporte de partículas salinas originadas no aerossol marinho que, com sua amplitude, as partículas de sais podem alcançar distâncias maiores antes de se depositarem [16] como o verificado na estação E1 (Figura 10) que demonstra o alcance das partículas salinas mesmo a $10 \mathrm{~km}$ de distância do mar.

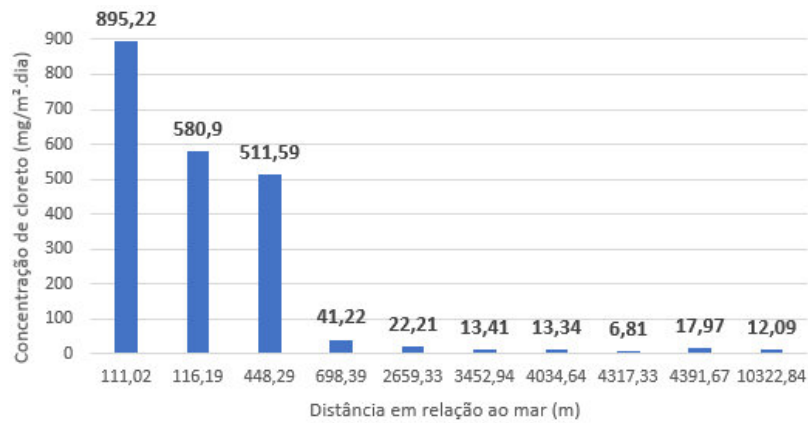

Figura 10: Gráfico da influência da distância em relação ao mar na concentração de cloreto.

Fonte: Autores (2017).

\section{Conclusões}

As concentrações de cloreto durante os cinco meses de estudo demonstraram ser influenciadas pelos parâmetros climáticos, distância em relação ao mar, altitude e presença de obstáculos. 
Dentre os parâmetros climáticos, umidade, temperatura, precipitação pluviométrica e o vento, este último é o principal fator climático que influencia as concentrações dos íons, em face de ser 0 responsável pela formação do aerossol marinho além de ser o principal meio que transporta os cloretos. 0 fator distância em relação ao mar comprova a afirmação, a partir de estações localizadas a grandes distâncias do mar que ainda assim apresentam concentrações de cloretos significativas na sua atmosfera.

Em relação a altitude, influenciada pelo efeito gravimétrico, as estruturas prediais próximas ao mar, nos pavimentos inferiores são degradadas com maior frequência e intensidade pelos íons cloretos quando comparadas com pavimentos superiores em face das partículas maiores serem mais densas e se depositarem em altitudes mais baixas.

O crescimento urbano e a otimização do espaço imobiliário motivam a construção de edifícios mais altos, que consequentemente resultam em obstáculos que influenciam as concentrações de cloretos nas regiões envolvidas. Por conta dessas barreiras, originam-se microclimas localizados que não são previstos pelas classes de agressividade ambiental da ABNT NBR 6118/2014, por somente apresentar classes que se referem ao macroclima de uma região, sendo assim estruturas em microclimas são projetadas de acordo com características não condizentes com o local da construção, resultando em uma possível degradação da estrutura no futuro.

Conclui-se com os estudos que é de extrema importância mapear as concentrações de cloretos na atmosfera marinha urbana de Aracaju para que se possa adequar os projetos estruturais correntes, que só priorizam basicamente as propriedades mecânicas resistências e deformações, com as propriedades físico-químicas características das agressividades ambientais. Com isso, sugere-se a criação do "projeto de durabilidade das estruturas" para o atendimento da vida útil requerida pelas normas de desempenho vigente.

\section{Referências}

[1] SOUZA, V. C.; RIPPER, T. Patologia, recuperação e reforço de estruturas de concreto. São Paulo: Pini, 1998.
[2] HADLEY, H. M. Concreto em água do mar - necessária revisão do ponto de vista. São Paulo: ABCP, 1948.

[3] PELLIZZER, G. P. Análise mecânica e probabilística da corrosão de armaduras de estruturas de concreto armado submetidas à penetração de cloretos. 2015.

[4] IBGE. Atlas geográfico das zonas costeiras e oceânicas do Brasil. p.118. Rio de Janeiro: IBGE, 2011.

[5] LIMA, M. G. et al. Durabilidade de estruturas de concreto em ambiente marinho importância dos estudos envolvendo microclima. 2005.

[6] Associação Brasileira de Normas Técnicas (ABNT). NBR 6211:2001 - Corrosão atmosférica Determinação de cloretos na atmosfera pelo método da vela úmida.

[7] American Society for Testing and Materials. ASTM INTERNATIONAL D 512-89. Standard test methods for chloride ion in water.

[8] SILVA, F. A. S. Avaliação do teor de íons cloreto no ar atmosférico da praia do futuro em Fortaleza/CE. 2011.

[9] ARGENTON, A. Conceitos fundamentais de Cromatografia a líquido de Alto Desempenho (HPLC). 2010.

[10] VILASBOAS, ]. M. L. Estudo dos mecanismos de transporte de cloretos no concreto, suas inter-relações e influência na durabilidade de edificações na cidade do SalvadorBA. 2013.

[11] ALVES, A. M. C. Contribuição à análise da perspectiva de vida útil de estruturas em concreto face ao teor de cloreto registrado em Maceió-AL. 2007.

[12] MEDEIROS, M. H. F.; GOBBI, A. RÉUS,G. C.; HELENE, P. Influência da altura e posição da edificação na penetração de cloretos: Estudo de caso em obra no Rio de Janeiro - Brasil. In:VI CONGRESO INTERNACIONAL SOBRE PATOLOGÍAS

http: / / dx.doi.org/10.25286/repa.v4i1.934 
E RECUPERACIÓN DE ESTRUCTURAS - Córdoba, 2010.

[13] PONTES, R. B. Disseminação de íons cloreto na orla marítima do bairro de Boa Viagem, Recife-PE. 2006.

[14] ALBUQUERQUE, F. F. Atualização do mapa de agressividade ambiental de Salvador-BA com dados de deposição de cloretos. 2016.

[15] PETELSKI, T.; CHOMKA, M. Sea salt emission from the coastal zone. Oceonologia, $v$. 42, n.4, p. 399-410, 2000.

[16] PEREIRA, L. F. L. C.; CINCOTTO, M. A. Determinação de cloretos em concreto de cimento Portland: Influência do tipo de cimento. In: Boletim Técnico da Escola Politécnica da USP, São Paulo, 2001. 